\title{
THE NERVOUS CHILD.
}

\section{By R. G. GORDON, BATH.}

THere is an aspect of the study of the nervous child which is worth considering, although it is necessarily highly speculative, and that is the psychological and physiological basis of his mental peculiarities, for unless we have a policy to guide us our treatment will be empirical and haphazard. Such haphazard and discontinuous treatment will defeat the end in view to a greater extent in the case of the nervous child than in any other branch of therapeutics. If a child is brought to us because his attitude to life is not normal, we must not only inquire how he behaves, but also ask why does he behave in this way. To answer this last question there are three lines of inquiry which may be followed up : (1) What initial equipment did he start with-what was his predisposition? (2) What has been and is the influence on his mind of his bodily functions, the secretions of his ductless glands, the efficiency of his digestion, renal function and so on? These are questions of temperament. (3) What have been and are the outside events which constitute his experience? In answer to the first question, from the psychological point of view, we may follow the arguments of McDougall ${ }^{1}$ and Shand, ${ }^{2}$ and postulate that the child is endowed with certain innate dispositions having the character of instincts and presenting for our examination a cognitive, affective, and conative aspect. McDougall has enumerated these, describing seven well-defined instincts of flight, repulsion, curiosity, pugnacity, subjection, self-assertion and the parental instinct, four less well-defined instincts of sex, gregariousness, acquisition, and construction, and the general innate tendencies of sympathy, suggestion and imitation, which are the affective, cognitive, and conative aspects respectively of the same tendency.

He then argues that the influence of temperament and environment working on this given material builds up the compound emotions, the sentiments and the character as a whole. Although these units of McDougall are capable of being connected with lower level processes, and are by no means unanalyzable as he claims, they serve as a useful starting point for psychological discussion. Suppose for a moment we consider this disposition as we would a prescription and think of the mental equipment of a child as consisting of so much pugnacity, so much curiosity, so much sex and so on. It must be admitted that at present we have no means of evaluating these dispositions in a 
quantitative way, yet observations of the behaviour of different children will give us a rough idea of how these units are proportioned. There can be no question that they do vary relatively to each other in different individuals and that this variation occurs within fairly wide limits. It is quite clear that one little boy has more pugnacity than another, while a third may have more curiosity, and so on. But within the limits of what is called 'normal,' this variation is as a matter of fact restricted, and no one instinctive unit can find expression entirely out of proportion to the rest. The nervous child is the child who does not achieve adaptation to his environment in the various stages of his growth. The individual cannot be studied apart from his environment, and his growth is or should be like the ever-widening circles caused by the disturbance of a still surface of water ; as Janet $^{3}$ puts it, his individual development should be commensurate with the increasing radius of his activity. Freud has laid stress on how this growth may be lopsided and how certain elements in the individual's character may be checked in their development by repression, and, remaining as infantile communities in an adult state, disturb the asymmetry of interaction between the individual and his environment; moreover, neurotic symptoms are definitely traceable to this asymmetry of growth. In some cases it is possible to discover that this asymmetry started at such and such an age as a result of such and such an experience, or the realization of some physical defect. The more we study these cases the more convinced we become, that although such incidents or the recognition of such defects may be the last straw that broke the camel's back, in many, if not in most, we have to trace this asymmetry right back to the innate dispositions, and I believe that many children are nervous because of a want of due proportion between their innate tendencies. To get back so far as this with any degree of clarity or certitude is extremely difficult in most cases, as any given personality, even that of a child, is a very complex affair. But, although we cannot estimate the proportions of the various elements with any precision, we may recognize in the nervous child behaviour which depends on combinations of these, which is not precisely similar to the behaviour induced by similar combinations in the so-called normal child. McDougall has analyzed the more complex emotions with great skill, but, as Lloyd Morgan ${ }^{4}$ has pointed out, he has not perhaps laid enough stress on the emergent quality of the resulting combination of these simpler factors. This conception of emergence is one which is likely to be of great service to psychology. It is not, in fact, new, but is only just being drawn out from the shadowy realm of academic philosophy. The point is, that it is not enough to analyze the factors operating in the various functions met with throughout the universe. We have to postulate some new quality which emerges as the result of combination. This is familiar in the realm of chemistry, 
where a mixture of hydrogen and oxygen under certain environmental conditions results not in a simple mixture, but in a new individuality, water, which has all sorts of unique properties totally different from its derivatives. Lloyd Morgan, in his Gifford lectures, showed how the same law holds in the realms of life and of consciousness, and we may apply it for our present purpose. McDougall states that such an emotion as awe is made up of fear and self-abasement and curiosity, but he leaves out of account the new quality which emerges from the combination of these primary emotions. No doubt self-abasement, curiosity and fear do go to make up awe, but awe is not just a mixture of these ; it has a quality of its own which belongs to none of them. Further, the important point in the present argument is that it by no means follows that a compound of these ingredients will always emerge the same. Returning to the analogy of chemistry, this is at once obvious. The emergent depends on the proportion of the ingredients and on the environment at the time of formation of the compound. For instance, take chlorine and mercury - under certain circumstances we get calomel, and under other circumstances corrosive sublimate. So in the integrations of the simpler mental patterns into the more complex emotions and sentiments sometimes one emotion emerges and sometimes another. For example, a typical nervous child was strongly endowed with curiosityshe was always prying into forbidden subjects, especially sex ; strongly with fear-she would do nothing that threatened herself in any way; though not a bad swimmer, it was all that her governess could do to induce her to enter the swimming bath ; and strongly with self-abasement, for she was slow and rather backward, and could not keep pace with other children. However, there was certainly no awe developed in her; on the contrary, rather an aggressive type of behaviour was complained of by her elders. This aggressiveness was, no doubt, compensatory to hide from herself her real self-depreciation, and it may be said that there was no development of awe because there was no integration of the simpler emotions. This is to a certain extent true, and is important, yet there was an integration of sorts into a sly attitude towards things to which it is difficult to give a name; this I would regard as an emergence of a different type from awe, though composed of the same essential ingredients. In respect of the nervous child this factor of want of integration is an extremely important one. As an illustration, a boy of twenty was sent into hospital for supposed chorea. The history was that he had all his life been a nervous child, an only son and his mother's darling. It was very soon obvious that there was no real chorea, and that the boy was a typical mental defective, with bodily deficiencies as well, such as kyphosis. He had only reached Standard II. at school, and exhibited the common lack of emotional and motor control often seen in such cases. In this case, then, there 
was a complete lack of integration and control, and he perhaps ought not to be included as a nervous child, but the parents seemed quite oblivious of there being anything wrong except that the poor boy was always ' so nervous.' It by no means follows, however, that the nervous, non-adaptable child is always backward; indeed, many such children are more than usually bright. For example, take the case of a boy of eleven. He was the despair of his aunt, who had brought him up since his mother's death, when he was three years old. He got on unusually well with his lessons when he would stick to them, but he was quite incapable of settling down at school, as he refused to obey his superiors or adapt himself to the other boys. At home he was worse, for he would not obey any one and would not stick at anything for long at a time. He was described as highly strung and nervous. There was no opportunity to go closely into his case, but he obviously had excessive curiosity and pugnacity and apparent self-assertion, though this might have been found to be a cloak for a real self-abasement had a fuller investigation been possible. Such ingredients might have been expected to produce ambition, but this was strikingly absent from the boy's personality. The reason for this may well have been the falsity of his self-assertion, but the most striking factor was the lack of integration of his whole character.

So far these features have only been described in psychological terms ; can we get any idea as to what underlies them if we consider them from the anatomical and physiological standpoint? To do this we have to go back to the basal unit of the reflex arc, which is built up and integrated at higher and higher levels, as Sherrington ${ }^{5}$ has shown. But, as Holt ${ }^{6}$ pointed out, it is not the individual neurones or the separate reflex ares which are important, but the way in which these are arranged ; it is that arrangement which constitutes the physiological basis of the human soul. Similarly, it is not so many wheels and rollers that make a printing press, but the arrangement of these wheels and rollers in a definite specific way; the essential feature of a printing press is the ' form of organization of the wheels and rollers.'

Most people do lip service to the theory that arrangements of neurones are in correlation with every mental process, but they are usually content to leave it at that, though McDougall emphatically repudiates any such method of approach to the problems of psychology. As it is impossible to observe a mental process going on in the neurone, the best we can do is to formulate a policy which seems to explain the facts, always being ready to throw it over when we get a better one. So far the most promising policy to follow would seem to be the mnemic theory of Richard Semon. ${ }^{7}$ Because he has invented a new vocabulary to express his concepts many find his view repellent, but in reality it is all clear and simple. His conception is that there are certain dispositions 
laid down, both in the germ cell and in the bodily structure of the individual. As a result of these dispositions, which he calls engrams, development and behaviour tend to follow certain definite lines. They are, however, capable of modification. They respond to certain patterns of stimuli by reason of the selective power of the receptors to which each corresponds-a familiar example being the tree, which puts out leaves every spring in response to atmospheric stimuli and its own inherent type of behaviour. These leaves are similar, but not identical to those of the preceding spring. Appropriate stimuli are followed by activation of the engrams, but after a state of quiescence is again reached the state of the engram is not the same as before. Hence, though revivals tend to be similar, they are never identical. When evolutionary progress has reached the stage of a complicated nervous system, certain engrams may be postulated which consist of special groupings of neurones with mental processes in correlation. The same mnemic laws apply to these, and although the same underlying type of behaviour results from the stimulation of these engrams, new groupings and integrations may occur, and by correlation new types of behaviour arise. The greater the multiplicity and complexity of neurones, the greater will be the potential modifications of engrams and the greater the elasticity of behaviour. Obviously it is in the human being that such potentialities reach their maximum, but modification of engrams and the correlated elasticity of behaviour are quite useless unless integration is possible into composite groups of engrams whose correlated behaviour is adapted to the needs of the individual in relation to the environment. It is just in this respect, as has been seen, that the nervous child fails. Why so ? What part of the nervous system is concerned with this higher integration of engrams which results in the proper correlation of behaviour so that it is adapted to circumstances, and controlled ? In the realm of motor activity, Hughlings Jackson and his followers have shown that adaptation and control are the function of the precentral cortex. Similarly, in the realm of sensation, Head ${ }^{8}$ had shown that the same functions are subserved by the postcentral cortex. More recently Bianchi ${ }^{9}$ has shown that the frontal lobes have the same function with regard to the so-called emotional reactions or instinctive dispositions of McDougall. He subjected certain monkeys to ablation of the frontal lobes and carefully observed their behaviour over long periods. Amongst other features observed, he notes that " none of the monkeys operated upon has shown the existence of that regulative and inhibitive power which it possessed prior to the operation. . . . The defect that is most outstanding consists in the entire absence of the higher sentiments, which represent a complication of the primitive emotions with numerous new factors. The sentiments of friendship, gratitude, jealousy, maternity, protection, dominion, authority, self-esteem, 
ridicule, and above all that of sociality-all these disappear after mutilation of the frontal lobes, whilst the primitive emotions remain sometimes even intensified, but not adapted for the struggle for existence. In all cases the conduct is seen to be incoherent. This incoherence is due to defect of imagination and of memory, to incapacity to represent and sustain an objective in the focal point of consciousness. The whole psychic tone is lowered ... and attention must be directed to the stereotypies and tics which are often met with." If Bianchi is correct in his interpretation of the functions of the frontal lobes, then there can be no doubt that integration of emotional dispositions depends on the proper working of this part of the nervous system. McDougall and Shand have shown that character and personality are built up on these emotional dispositions, and I have indicated that it is here that the nervous child fails. We must presume, then, that there is something the matter with his frontal lobes. That this is nothing gross is obvious, for the nervous child is not lacking in capacity, and frequently ' grows out of ' his nervousness and becomes a normal and useful citizen. I would suggest that there is no deficiency of frontal neurones, as is the case in the idiot and imbecile, but that these do not get integrated into the requisite engrams. There is, to use Janet's old expression, a lack of psychological synthesis, a failure of the synapses to get together. Such terms are, however, merely descriptive, and an explanation of the failure of integration is more difficult. In my opinion there is no one law to cover all cases. It must be remembered that at the level of the frontal lobes we are dealing with the most recently acquired and, consequently, most easily disturbed and delicately adjusted structures. To use a hyperbole, at spinal levels a crowbar is needed to disturb function ; but at frontal lobe levels an angry word is all that is required. To say that the nervous child lacks the normal inhibitions is almost equivalent to saying that he lacks normal integration, for all evidence, both psychological and neurological, points to the fact that inhibitions are especially imposed by higher functions on the exuberant manifestations of lower activities. Witness the effects of removal of cortical control in liberating convulsive seizures in the motor realm or in the sensory realm, the unrestrained affective reactions when the thalamus is liberated from cortical influence. Bianchi suggests that inhibition depends, at any rate to some extent, on the length of the path which has to be traversed before the final motor path is reached, and so any short-circuiting which may occur will reduce inhibitions. I think this view of inhibition must be taken with a certain amount of reservation, but it is certainly suggestive that a cutting out of the frontal lobes with all their intricate neurone paths does result in the most remarkable diminution of inhibitions. Why, then, should these frontal neurones fail in their function to exert control over the rest ? In certain cases, such 
as the congenital psychasthenics described by Janet, ${ }^{10}$ there is something inherent which prevents integration. What that is we have not the slightest idea. In other cases nutritive deficiencies, lack of vitamines, etc., seem to be responsible, for when these are remedied improvement occurs. This is more noticeable in young children, whose nervousness is manifested in fits of temper and screaming, and sometimes in faints or fits. As illustration, I may take the case of a child aged nine, whose mother stated that he suffered from fainting attacks, uncontrollable temper and a general nervous attitude towards life. The stools showed undigested fats, and liver efficiency was reduced. Reduction of fat in the diet, with a more generous provision of vitamines, resulted in a much more normal behaviour, and eventually in apparently complete recovery.

Various poisons and infective agencies are frequently responsible, and those of syphilis and encephalitis are specially noticeable in this respect.

Finally, similar results may ensue, as Freud and his followers have shown, if the child is placed in an environment in which circumstances reacting on his personality make for conflict between various emotional dispositions instead of making for their integration. I am convinced that this environmental factor is of great importance and should never be lost sight of, and that unfortunate family frictions and unbalanced attachments to parents are more prejudicial to the normal development of the child than anything else.

In any case, whichever line of approach is taken, there is a tendency to try to dissociate the individual from his environment for descriptive purposes, but this is misleading, and it cannot be too often reiterated that a personality is meaningless except in relation to his environment. This error is specially liable to occur amongst those who approach the subject from the neurological standpoint, and must be carefully avoided.

Let it not be thought that because we try to express the pathology of the nervous child in terms of neuropathology rather than in terms of psychopathology, this means that treatment is less called for or less likely to be successful. The higher the level the more easily is function disturbed, but also the more easily is it restored. All neurologists are familiar with the possibilities of re-education of cortical function in the motor realm, where irreparable destruction has not been too extensive. Careful experiments by Graham Brown and Stewart ${ }^{11}$ have shown how cortical function may be restored in the sensory realm by re-education, and less exact observations indicate the same possibilities in the experience of most workers. Still more, then, is it possible to modify and improve the functions of the frontal lobes, and much can be done in most cases provided care is taken to discover exactly what is amiss, which dispositions are disintegrated and out of control, how this dis- 
integration came about or what influence is preventing the due development of the personality. For this purpose a certain amount of analysis is essential, though the complete psychoanalytic procedure is seldom, if ever, necessary or advisable, the risk of making the child too introspective at an age when he is incapable of discriminating values being too great. But if psychological investigation is important, so is adequate physical examination, for one has known of cases in which many hours and much labour have been lost in futile or almost futile psychological analyses when attention to a physical defect, such as eye-strain, or deafness, or a digestive abnormality, was all that was necessary to change the course of the child's existence.

\section{REFERENCES.}

IICDougall, W., Social Psychology, London, 1917.

2 SHAND, A. F., Foundations of Character, London, 1920.

3 JANET, P., "La tension psychologique," Brit. Jour. Psychol., Med. sect., 1920,1 .

4 Lloyd Morgax, C., Emergent Evolution, London, 1923.

5 Sherrington, C. S., Integrative Action of the Nervous System, Oxford, 1906.

6 HoLT, The Freudian Wish, London, 1917.

7 SEMon, R., The Mneme, London, 1916.

8 HEAD, H., Studies in Neurology, London, 1920.

9 Braxchi, L., Mechanism of the Brain and the Function of the Frontal Lobes, Edinburgh, 1922.

10 Janet, P., Les obsessions et la psychasthénie, Paris, 1889.

11 GRAhaM Brow, T., and STEWART, R. M., Brain, 1916, xxxix, 348. 